\title{
LA CARACTERIZACIÓN DEL PAISAJE DE MENORCA A TRAVÉS DE LA TOPONIMIA
}

\author{
Antoni Ordinas Garau y Jaume Binimelis Sebastián \\ Departamento de Ciencias de la Tierra \\ Universitat de les Illes Balears
}

\begin{abstract}
"De tal modo las palabras llevan la esencia humana de las cosas, que las que son nombres propios, los geográficos, los toponímicos, llevan un paisaje, y a las veces basta sólo con oír la palabra para adivinar lo que pueda ser la tierra que recibió aquel nombre".

Miguel de Unamuno y Lugo

(El poder de la palabra, 1931)
\end{abstract}

\section{RESUMEN}

La toponimia constituye un excelente indicador del paisaje y el espacio geográfico. A través del análisis tanto cualitativo como cuantitativo de los topónimos que identifican y frecuentemente describen el territorio, se puede obtener un profundo conocimiento de su geografía, a menudo ampliada con numerosas referencias a su evolución histórica. Los nombres geográficos de Menorca nos han permitido detectar los elementos geográficos más representativos del paisaje de la isla confirmando los principios de transparencia y de significación territorial formulados por algunos geógrafos pioneros en abordar el vasto y fructífero campo que comparten la toponimia y la ciencia geográfica.

Palabras clave: Toponimia, geografía, paisaje, significación territorial, Menorca.

\section{ABSTRACT}

\section{Minorca island landscape characterization through toponymy}

Toponymy is an excellent indicator of the landscape and geographical space. A deep understanding of its geography can be achieved through the qualitative and quantitative analysis of toponyms which identify and frequently describe the territory, often increased with large references to its historical evolution. The geographical names of Minorca have allowed us to detect the most representative geographic components of the landscape of the island, proving the principles of transparency and territorial significance formulated by some geographers who were pioneers to deal with the huge and productive field shared by toponymy and geographical science.

Key words: Toponimy, geography, landscape, territorial significance, Minorca.

\section{MENORCA, TERRITORIO INSULAR MEDITERRÁNEO}

En la isla de Menorca, segunda en extensión $\left(701,8 \mathrm{~km}^{2}\right)$ de las Baleares, con el 14\% de la superficie total, el impacto humano sobre el medio natural ha sido menor que en el resto del archipiélago y de muchos otros territorios insulares del Mediterráneo. Su configuración geológica ha determinado la división de la isla en dos regiones naturales: la Tramuntana y el Migjorn. En la primera, que se extiende sobre la mitad septentrional, predomina un relieve ondulado sobre afloramientos de materiales silíceos del paleozoico, impermeables, y otros calcáreos del secundario, donde predomina una vegetación de encinares y matorrales de brezo. La segunda, que ocupa la restante mitad meridional, se caracteriza por la presencia 
de pinares, acebuchales y vegetación arbustiva que se extienden sobre un sustrato calcarenítico arrecifal del mioceno superior extremadamente permeable. Sin embargo, la actividad agraria y, especialmente la ganadera, se halla presente, indistintamente, en ambas regiones en las que se ha alterado la vegetación y el medio natural dando lugar a un paisaje donde los cercados, delimitados por muros levantados mediante la técnica de la piedra en seco y dedicados a herbáceos (pastos, forrajes y cereales), constituyen el principal elemento del paisaje rural menorquín. No en balde, Menorca es el territorio balear donde el sector primario conserva mayor protagonismo, aunque tampoco haya quedado al margen del proceso de terciarización y especialización turística desarrollado durante las últimas décadas y que se ha traducido en una progresiva urbanización de algunos sectores del litoral, aunque el grado de intensidad de este proceso haya resultado menor que el del resto de las islas mayores del archipiélago. Tales rasgos han favorecido la pervivencia de la toponimia tradicional y una menor presencia de la neotoponimia surgida de la expansión turística (Picornell, 1982) como reflejo, una vez más, de la realidad geográfica descrita a través de sus correspondientes nombres geográficos.

Figura 1. Situación geográfica de Menorca.

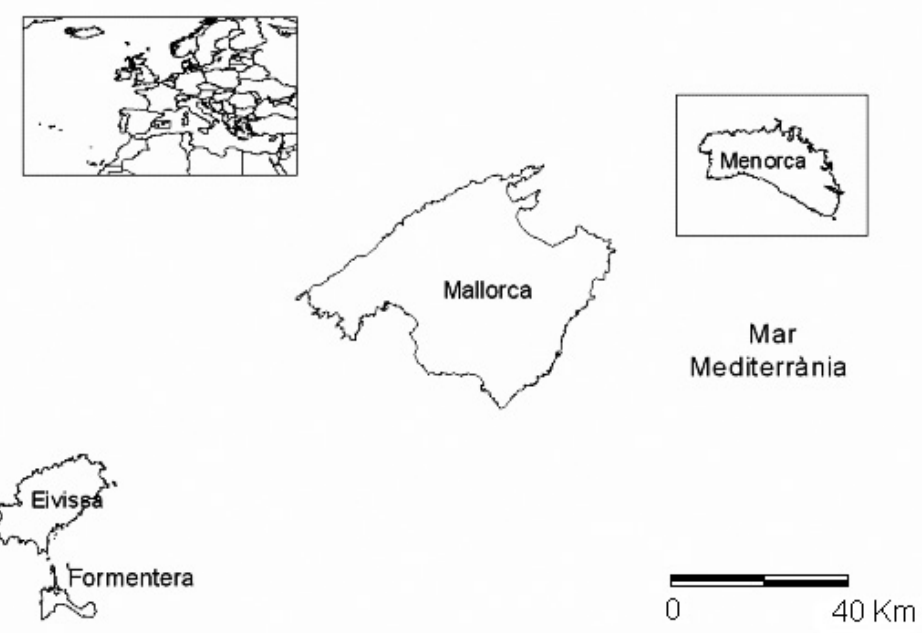

\section{LA TOPONIMIA, FUENTE PARA EL ANÁLISIS DEL PAISAJE Y DEL ESPACIO GEOGRÁFICO}

A pesar de la innegable interdisciplinariedad que atañe al estudio de la toponimia, la propia etimología

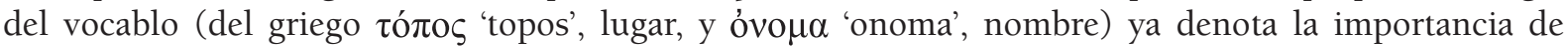
la localización geográfica como uno de los componentes básicos que intrínsecamente conforman los topónimos. De manera que abordando sólo el estudio del nombre y descontextualizándolo del lugar que designa, frecuentemente resulta problemático obtener información de forma completa y mínimamente garantizada. Prueba de ello son los errores cometidos en muchas etimologías propuestas y que pudieran haberse evitado con una simple visita al lugar referido, por lo que se puede afirmar, desde la perspectiva geográfica y en un ejercicio lúdico de las palabras, que la toponimia sin "topo" es "nimia".

A la evidente función identificadora de los topónimos cabe añadir una función descriptiva y, por tanto, de carácter muy geográfico al entroncar con la etimología misma de la geografía, descripción de la Tierra. De hecho, la descripción, método imprescindible para la formación del conocimiento geográfico, aparece en la mayoría de los topónimos, aunque no todos ellos presenten el mismo grado descriptivo, lo que ha permitido distinguir entre topónimos plenamente descriptivos y otros que sólo lo son indirecta o parcialmente, obviando los que carecen de dicha cualidad (Tort, 2000). La extracción e interpretación de la información que transmiten los dos primeros grupos es la que permite al geógrafo obtener abundante y valioso material sobre la configuración de un determinado territorio y de la caracterización del paisaje.

Aunque el interés y estudio de los topónimos (también conocidos como nombres de lugar o, más significativamente aún, nombres propios geográficos) pueda remontarse a épocas más o menos lejanas, su 
estudio desde el ámbito científico de la geografía se ha ido desarrollando en tiempos mucho más recientes y especialmente si se circunscribe en el entorno de la geografía española. No obstante, el carácter plural e interdisciplinario de la toponimia en el que la geografía juega un importante papel ya fue descrito más de medio siglo atrás por el inglés Darby (1957) y el canadiense Poirier (1965). Antes y después han sido muchos los autores que han defendido explícitamente el valor geográfico de la toponimia, como Paul Vidal de la Blache, Carl Sauer o Pau Vila, y que han reiterado, desde diversas disciplinas, la privilegiada relación entre toponimia y geografía, destacando especialmente la obra del geógrafo canadiense Henri Dorion, de referencia ineludible a nivel internacional por sus trabajos de toponimia aplicada a la geografía y en donde se fundamentan algunos de los principios teóricos (Dorion, Poirier; 1975). Tampoco resultan ajenas las apreciaciones de algunos geógrafos, entre los que destaca Carl O. Sauer, padre de la geografía cultural, para quien el vocabulario geográfico local y la toponimia constituyen un sustrato de saber que, entre otras, evidencia la estrecha relación entre la terminología geográfica y la toponimia (Sauer, 1956). El propio Vidal de la Blache (1888-1889) ya se refería a los topónimos como "fuentes vivas de la geografía" y señalaba la profunda imbricación entre el país y los nombres del país, una imbricación que, como señala Tort (2012), es equivalente, a distinta escala, a la que se da entre los lugares y sus nombres o topónimos.

En nuestro país, a pesar de un interés más tardío de los geógrafos por la toponimia, éste ha ido creciendo a lo largo de los últimos años con la incorporación de nuevos geógrafos y la multiplicación de trabajos realizados, destacando las aportaciones metodológicas y epistemológicas del geógrafo J. Tort (2003), relativas a la toponimia como fuente descriptiva y explicativa del territorio y de sus paisajes; así como la abundante y variada producción del profesor Rosselló (2004). A pesar de nuestra ya larga trayectoria de recolección y estudio toponímicos que se remonta a la década de los 80 y que cuenta con una primera aproximación a la terminología relativa a la toponimia y el paisaje de Menorca publicada una década más tarde (Ordinas, 1993), los principios teóricos de transparencia, excepcionalidad y significatividad territorial enunciados por Tort (2001) y que suponen una de las principales aportaciones para la interpretación y análisis del paisaje a través de la toponimia, se convierten en el presente trabajo en guía y referencia para su aplicación al binomio paisaje-toponimia de la isla de Menorca.

Para llevar a cabo nuestro objetivo y a pesar de existir alguna recolección toponímica relevante, como la realizada por el pionero Mascaró (1946-1951) en el que se convertiría en el primer mapa toponímico de la isla, así como algunos trabajos destacados en dicha temática además de los del propio Mascaró, hemos trabajado a partir del mayor corpus toponímico hasta ahora obtenido de la isla de Menorca y en cuya recolección participamos personalmente. Se trata de la toponimia obtenida para vestir el Mapa Topográfico Balear a escala 1:5.000 cuyo trabajo de campo se desarrolló a lo largo de una campaña en 1990 y con el que se consiguieron reunir 6.715 topónimos, cifra de la que se deriva una densidad de 9,5 topónimos $/ \mathrm{km}^{2}$ como fruto de las doscientas entrevistas efectuadas sobre el terreno a otros tantos informadores, seleccionados por su especial conocimiento de una determinada área del territorio sobre la que fueron interpelados.

\section{PRECEDENTES EN EL ESTUDIO GEOGRÁFICO DE LA TOPONIMIA DE MENORCA}

Al margen de un importante número de publicaciones relativas a la toponimia de Menorca (Ordinas, 1994) bajo diversos enfoques (cartográfico, lingüístico, histórico...), nos interesa particularmente centrarnos en aquellas que han tratado la toponimia menorquina desde un interés más específicamente geográfico. En este sentido, después de una primera aproximación de carácter general (Ordinas, 1991), abordamos la estrecha relación entre la toponimia y la terminología geográfica, especialmente la referida al medio físico (Ordinas, 1992) y más concretamente la orográfica (Ordinas, 2004), del mismo modo que otros autores como Rosselló (2001) y Grimalt, et al., (2009) hicieron lo propio centrándose en la vegetación. De hecho, el aprovechamiento de la toponimia como instrumento de análisis geográfico ha experimentado un notable desarrollo a lo largo de las últimas décadas en Baleares, focalizado en buena parte por la actividad de algunos miembros del departamento de Geografía de la Universidad y destacando específicamente en la interpretación del paisaje vegetal a través de la fitotoponimia que lo ha convertido en un campo de estudio prolífico tanto a nivel global (Caldentey, et al., 2006b), (Grimalt, et al., 2006), como por el análisis de la distribución vitícola (Caldentey, et al., 2006a), o de maquias (Ordinas, et al., 2007). 


\section{CLASIFICACIÓN Y DISTRIBUCIÓN GEOGRÁFICA DE LA TOPONIMIA DE MENORCA}

La rotulación cartográfica de la toponimia exige su codificación y para ello cada uno de los topónimos debe ser clasificado atendiendo a diversos parámetros entre los que destacan el de su magnitud (extensión, longitud, altura...) y el de su identificación o realidad geográfica que no siempre se corresponde con la que su nombre (el topónimo) indica y prestándose, en tales casos, a una claro equívoco. Así pues, la propuesta de codificación del Institut Cartogràfic de Catalunya (ICC), organismo encargado del levantamiento del mapa, es la utilizada para nuestro estudio y a través de la que podemos conocer, mediante un análisis cuantitativo de la distribución temática de los topónimos que nos ofrece su clasificación, las principales características geográficas del conjunto de la toponimia menorquina.

Una primera aproximación a la configuración de la realidad geográfica a través de los nombres que la identifican y siguiendo una dicotomía de gran tradición en nuestra ciencia, nos permite distinguir dos grandes bloques: el poblamiento y el medio físico. Una simple ojeada sobre las cifras que expresan su contabilidad ya permite extraer, como rasgo fundamental, el predominio de la toponimia relativa al medio físico $(67,5 \%)$ frente a la del poblamiento $(32,4 \%)$. Este dato resulta ser bastante significativo y más aún si lo comparamos con la media del archipiélago balear donde la diferencia entre ambos porcentajes se reduce con un $56 \%$ y un $43 \%$, respectivamente. No obstante, en la tabla 1 se puede observar con mayor detalle el balance general de la contabilidad toponímica de Menorca.

Tabla 1. Recuento de la toponimia de Menorca.

\begin{tabular}{|l|c|}
\hline Topónimos relativos a: & $\mathrm{N}^{\mathrm{o}}$ \\
\hline POBLAMIENTO: LUGARES DE HABITACIÓN PERMANENTE & 1.442 \\
\hline POBLAMIENTO: IMPLANTACIÓN INDUSTRIAL & 42 \\
\hline POBLAMIENTO: SERVICIOS DE COMUNICACIÓN Y TRANSPORTE & 392 \\
\hline POBLAMIENTO: SERVICIOS COMUNITARIOS & 223 \\
\hline TOTAL POBLAMIENTO & 2.099 \\
\hline MEDIO FÍSICO: OROGRAFIA TERRESTRE Y MARÍTIMA & 3.857 \\
\hline MEDIO FÍSICO: HIDROGRAFIA & 521 \\
\hline TOTAL MEDIO FÍSICO & 4.378 \\
\hline SIN CODIFICAR & 238 \\
\hline TOTAL & 6.715 \\
\hline
\end{tabular}

\subsection{La toponimia relativa al poblamiento}

La toponimia relativa al poblamiento se halla subdividida en cuatro grandes grupos relativos a lugares de habitación, implantación industrial, servicios de comunicación y transporte, y servicios comunitarios. Entre ellos, destaca el grupo referido a los lugares de habitación permanente al reunir más del 68\% de la toponimia humanizada, lo que contrasta con el grupo de los topónimos indicadores de la implantación industrial, situados en el extremo opuesto por su escasa presencia.

Figura 2. Toponimia relativa al poblamiento.

\section{Poblamiento}
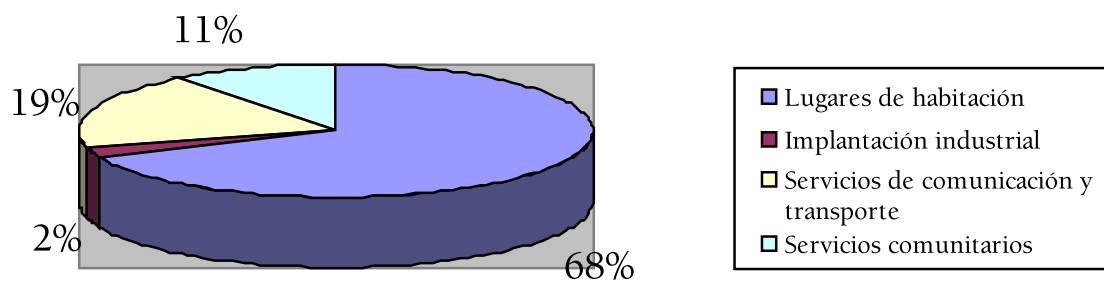


\subsubsection{Lugares de habitación permanente}

Constituyen el grupo mayoritario entre los topónimos indicadores del poblamiento y se dividen en tres subgrupos: topónimos relativos a núcleos de población, partes de un núcleo urbano y edificaciones aisladas. Forman parte del primero ciudades, pueblos, villas, aldeas y urbanizaciones que, en conjunto, sólo suponen el 5,6\% de los lugares de habitación permanente, porcentaje que refleja fielmente el menor impacto urbanizador y depredador del territorio del que goza la isla de Menorca en comparación al resto del archipiélago.

En el subgrupo relativo a las partes de un núcleo urbano se incluyen los barrios, avenidas, paseos y plazas más importantes. Con sólo un 4,5\% se convierten en el menor de los subgrupos definidos, aunque su escasa significación se debe en buena parte a que la recolección toponímica de carácter urbano ha sido muy selectiva y reducida.

En cambio, las edificaciones aisladas, es decir, aquellas situadas fuera de núcleo urbano, constituyen el grupo mayoritario con un $89,8 \%$ de los topónimos correspondientes a los lugares de habitación, a la vez que suponen el $61,7 \%$ del total de los topónimos relativos al poblamiento en general. Se subdividen, a su vez, en dos grupos: edificaciones aisladas propiamente dichas (casa de lloc, estància, casa aislada, molino...), abrumadoramente mayoritarias con un $89,2 \%$ de su subgrupo, y edificaciones aisladas habitadas o no temporalmente (barraca, cabaña, cobertizo...) que tan sólo suponen el 10,7\% restante, con lo que queda patente su desigual presencia. No obstante, la escasa representación toponímica de las edificaciones de segundo orden no refleja en justa medida su presencia real, pues su ínfima categoría junto al estado ruinoso en que se encuentran muchas de ellas es la causa de que cierto número no hayan sido recogidas y registradas toponímicamente. Aún así, debemos señalar que la toponimia relativa a la población en diseminado de Menorca es menor que la registrada en Mallorca e Ibiza. Ello se debe a que en el caso de Menorca la población en diseminado queda limitada prácticamente a los $l l o c s{ }^{1}$ que, aún siendo relativamente numerosos, presentan todavía una baja densidad relativa. Contrasta, por tanto, la media y gran propiedad menorquina, poco fragmentada, con el caso de la mayor de las Pitiusas, donde se produce el extremo opuesto: pequeñas propiedades, producto de una tradicional y repetida fragmentación como consecuencia del legado de generaciones, donde se levanta una vivienda unifamiliar permanente dando lugar a su característico poblamiento intensamente diseminado.

Figura 3. Toponimia relativa a lugares de habitación.

\section{Poblamiento: lugares de habitación}
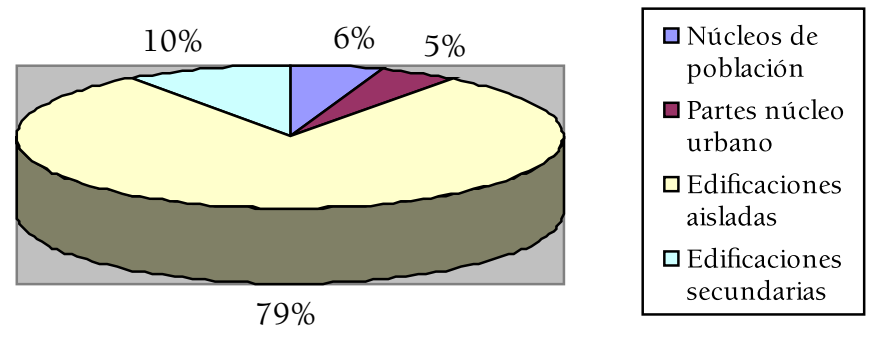

\subsubsection{Implantación industrial}

También como fiel reflejo de la realidad menorquina, la representación toponímica relativa a la implantación industrial resulta muy escasa, con apenas un 2\% de los topónimos correspondientes al poblamiento. Aunque la clasificación toponímica contempla la posibilidad de un amplio abanico de especialización industrial (centros productores de energía, industrias agroalimentarias, de la construcción, de la electricidad y la electrónica, de la madera y el corcho, del metal, del papel, de reciclaje, extractivas,

\footnotetext{
1 Lloc es el nombre genérico que en Menorca identifica la masía, alquería o finca rústica extensa (unidad de explotación agraria) que alberga una casa aislada donde residen los payeses que la cultivan en régimen de aparcería.
} 
mecánicas, químicas, textiles, locales industriales abandonados, polígonos industriales, almacenes o depósitos, etc.) que demuestra su utilidad en otras regiones, resulta superfluo en el territorio isleño. A pesar de ello, también debemos señalar que gran parte de la toponimia relativa a la industria moderna resulta ser una neotoponimia de carácter comercial, alusiva a las marcas y frecuentemente sometida a unas condiciones de eventualidad que impiden su arraigo toponímico, características que la convierten en poco idónea para su implantación en la cartografía oficial que pretende ser objetiva y duradera y que no puede ni debe arriesgarse a reflejar este tipo de neotopónimos publicitarios o pseudopublicitarios. En definitiva, lo más relevante resulta ser el escaso peso de la toponimia relativa a la actividad industrial, una tendencia también extendida en el resto del archipiélago.

\subsubsection{Servicios de comunicación y transporte}

El 18,6\% de los topónimos relativos al poblamiento pertenecen a este grupo, aunque el 92\% de ellos corresponde a vías de comunicación (carreteras -comarcales y locales-, caminos -públicos y privados-, puentes, túneles...), en las que caminos y carreteras resultan mayoritarios. Aunque teóricamente también se incluyen aquellos topónimos relativos a las instalaciones para los medios de transporte en general (aparcamientos, aduanas, estaciones, terminales, apeaderos...) así como los servicios para el tráfico aéreo (aeropuertos, aeródromos, helipuertos, pistas, torres de control, faros aéreos...), su representación toponímica resulta irrelevante, con un 1,5\% en su conjunto. Algo más notoria, con un 6,3\%, resulta la representación formada por los topónimos relacionados con el tráfico marítimo (dársenas, faros, muelles, puertos...), mientras que son inexistentes tanto los relativos al transporte por ferrocarril, de los que Menorca carece y ha carecido históricamente, como los referidos a sistemas de transporte (gaseoductos, acueductos, líneas de alta tensión, torres de comunicaciones...).

Respecto a las vías de comunicación, puede llamarnos la atención la mayor representación toponímica de los caminos frente a las carreteras. La explicación reside -en además de la lógica mayor extensión de la red viaria secundaria que constituyen los primeros-, en que las carreteras han sido recogidas a través de su nomenclatura oficial, parcialmente numérica y frecuentemente desconocida por la población a la vez que totalmente alejada del concepto de toponimia popular, con el agravante, además, de aparecer multiplicada al repetirse en cada una de las hojas del mapa en las que aparece un tramo de la carretera en cuestión, por lo que dichas denominaciones oficiales no fueron introducidas en el corpus toponímico sobre el que trabajamos, limitándonos a la escasa toponimia popular que las identificaba. En cambio y paralelamente, la ausencia de una nomenclatura oficial, y de carácter numérico, relativa a los caminos, es la causa de la desigual representación toponímica de ambas tipologías viarias. Tampoco está de más recordar aquí las considerables dificultades que conlleva la toponimia viaria y que asimismo nos recuerdan las que experimenta la red hidrográfica, en el sentido que un mismo camino puede llegar a tener, por una parte, un topónimo distinto para identificar cada uno de sus tramos, cuyo nombre, a pesar de ser indeterminado, es frecuentemente proporcional a la longitud y/o a las características de su trazado. Por otra parte, un mismo camino, o tramo, puede ser identificado por más de un nombre, cualidad que generalmente guarda relación con la procedencia de los usuarios. Ante esta caótica casuística, resulta difícil objetar a la fría, aunque también precisa, nomenclatura oficial de las carreteras.

Figura 4. Toponimia relativa a servicios de comunicación y transporte.

\section{Poblamiento: servicios de comunicación y transporte}

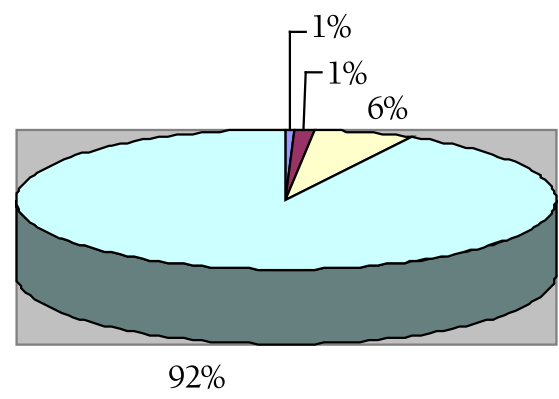

$$
\begin{aligned}
& \square \text { Instalaciones } \\
& \square \text { Tráfico aéreo } \\
& \square \text { Tráfico marítimo } \\
& \square \text { Vías de comunicación }
\end{aligned}
$$

$92 \%$ 


\subsubsection{Servicios comunitarios}

El último grupo de topónimos que hacen referencia al poblamiento supone el 10,6\% del total de la toponimia poblacional o humana. Está subdivido en diez apartados de desigual peso: centros administrativos (ayuntamientos, parlamentos, gobiernos civiles, juzgados, consulados...); centros comerciales (áreas de servicios, grandes almacenes, mercados, supermercados, gasolineras, cooperativas...); centros de servicios sociales (asilos, centros cívicos, cementerios, parques de bomberos, cárceles, bibliotecas...); lugares de interés histórico-cultural (castillos, ciudadelas, murallas, museos, necrópolis, poblados prehistóricos, atalayas, torres de defensa, torres de vigilancia, monumentos, acueductos, taulas, navetas, talayots...); centros docentes (academias, escuelas, colegios, escuelas técnicas, guarderías, institutos, parvularios, seminarios, universidades...); centros sanitarios (hospitales, clínicas, dispensarios, maternidades, sanatorios...); centros religiosos (monasterios, ermitas, capillas, oratorios, conventos, santuarios, iglesias, catedrales, basílicas...); centros de ocio (polideportivos, estadios, campos de deportes, piscinas públicas, plazas de toros, clubes náuticos...); hostelería (campings); y centros de investigación y señales (observatorios astronómicos o meteorológicos, y vértices geodésicos, respectivamente). Lo más destacado de la toponimia relativa a los servicios comunitarios de poblamiento es que el $61,9 \%$ corresponde a lugares de interés histórico-cultural (y especialmente a talayots, torres de defensa, taulas y navetas). De hecho, Menorca es la isla de mayor presencia y conservación de monumentos prehistóricos, convirtiéndose en uno de sus principales rasgos paisajísticos y territoriales.

Figura 5. Toponimia relativa a servicios comunitarios.

\section{Poblamiento: servicios comunitarios}
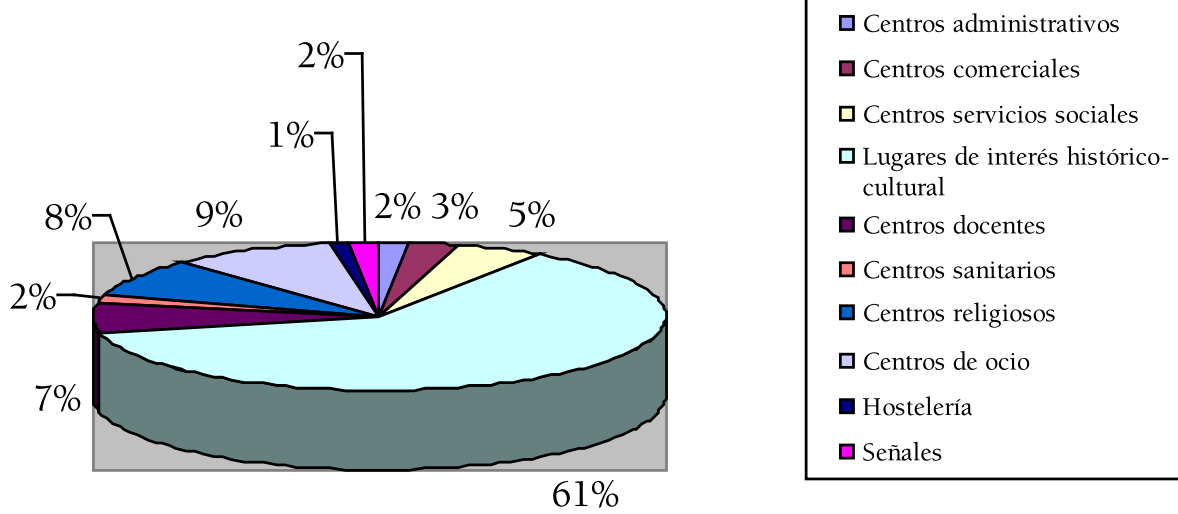

\subsection{La toponimia relativa al medio físico}

El medio físico, al que van referidos poco más del $67 \%$ de los topónimos, se encuentra dividido en dos grandes bloques de desigual representación. Se trata de la orografía terrestre y marítima (88\%) y la hidrografía $(11,9 \%)$. Sin embargo, paradójicamente, de la comparación con el resto de las islas, se constata la relativa pobreza oronímica de Menorca, ya que innumerables colinas, laderas, collados, vaguadas, etc, mayoritariamente no aparecen en la toponimia identificados como tales, sino que con demasiada frecuencia, al formar parte de los terrenos vallados o cercados (tanques) omnipresentes y que invaden la práctica totalidad del territorio, los accidentes orográficos pierden el protagonismo, desde el punto de vista toponímico, a favor de la parcela vallada que los encierra. Esta es básicamente la explicación de porqué tanto las prominencias como las depresiones del terreno son raramente registradas en la toponimia, especialmente interior, de Menorca. 
Figura 6. Típico paisaje menorquín en el término municipal de Ciutadella, donde la abundancia de piedra ha propiciado el levantamiento de cercados (tanques) y barracas (ponts de bestiar) para el refugio del ganado, todos ellos levantados con la tradicional técnica de la piedra en seco.

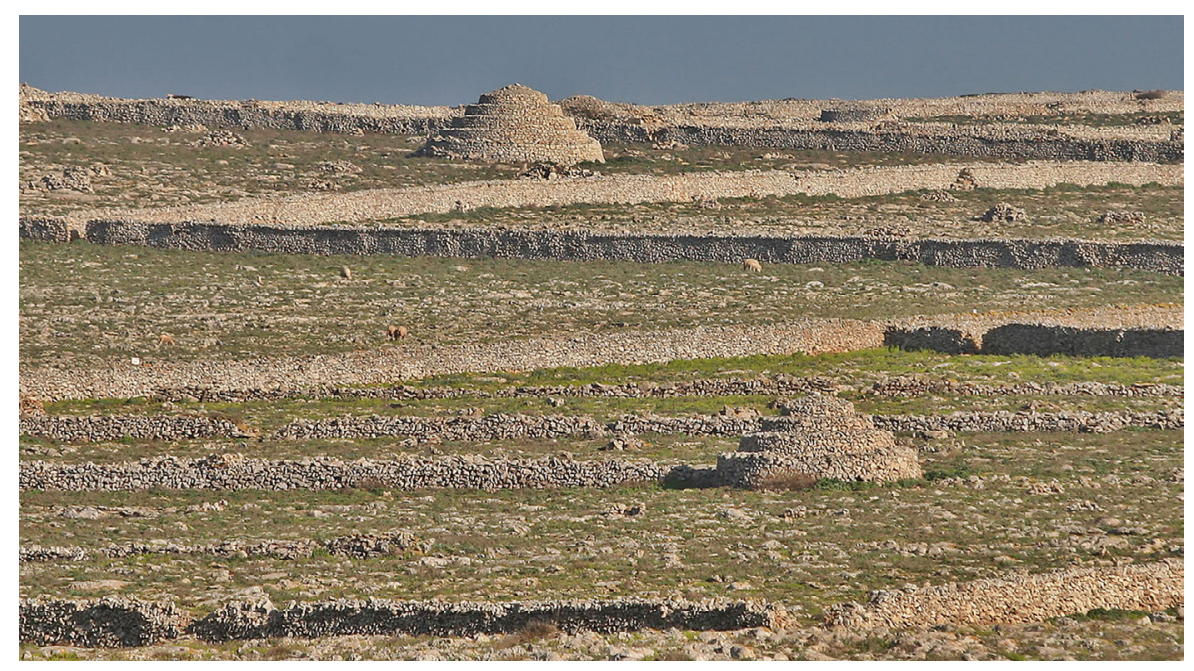

Figura 7. Toponimia relativa al medio físico.

\section{Medio físico}
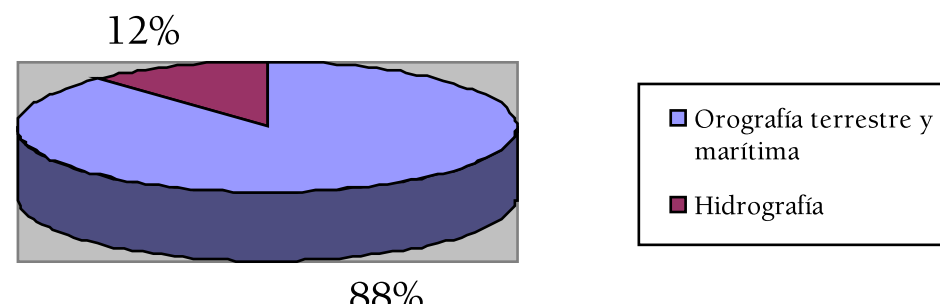

$88 \%$

\subsubsection{Orografía terrestre y marítima}

Los orónimos, topónimos referidos a la orografía, se han subclasificado en diez apartados: elevaciones del terreno en general, montañas y/o puntos elevados de una montaña, depresiones de la superficie terrestre, pasos a través de una cresta, acantilados, terrenos llanos, terrenos en pendiente, cavidades naturales, áreas, y relieves litorales marinos. En su conjunto se distinguen, como datos más relevantes, el destacado papel de los topónimos que identifican las áreas (58,7\%), seguidos de la toponimia litoral (24,3\%).

En cuanto a los topónimos que designan las elevaciones del terreno, es decir, aquellos que identifican macizos, montañas, sierras, cordilleras, colinas, cerros, etc., sólo contabilizan el 2,6\% de los oronímicos. Paradójicamente, la isla de Menorca presenta una importante merma en este tipo de topónimos debido frecuentemente, como ya se ha señalado, a su sustitución por el nombre de los cercados en los que se hallan. Las prominencias que culminan en los puntos más elevados de una montaña u otra elevación en general, identificadas mediante genéricos como agulla, cresta, bony, cap, penya, puig, punta, roca... suman el 2,3\%, aunque los más presentes son punta, cap, penya y, sobre todo, puig, pues en las islas éste se convierte en el genérico oronímico por antonomasia al designar cualquier elevación de cierta magnitud (Vid. Figura 8).

Por su parte, los genéricos coll, coma, comellar, clot, vall, estret... son los más habituales a la hora de identificar las depresiones del terreno, un escaso $0,7 \%$ de la oronimia menorquina. También los nombres relativos a los pasos a través de una cresta (pas) obtienen aquí una anecdótica representación, con apenas el $0,1 \%$. Las menores dificultades de acceso que presenta la orografía menorquina muy probablemente expliquen tan escasa representación que contrasta con la que ofrece la isla de Mallorca, en concordancia con la magnitud y extensión de sus áreas montañosas y, especialmente, de la Serra de Tramuntana. La 
escasez es también un rasgo característico de la toponimia relativa a la verticalidad del terreno $(0,75 \%)$ que, en el caso de Menorca, muchas veces localizamos en el litoral en forma de acantilados.

Figura 8. El Toro, en el municipio de es Mercadal. Sus 350 m marcan la máxima cota de la isla de Menorca. En sus estribaciones, el característico paisaje menorquín (bocage) utilizado para pastos de la ganadería vacuna.

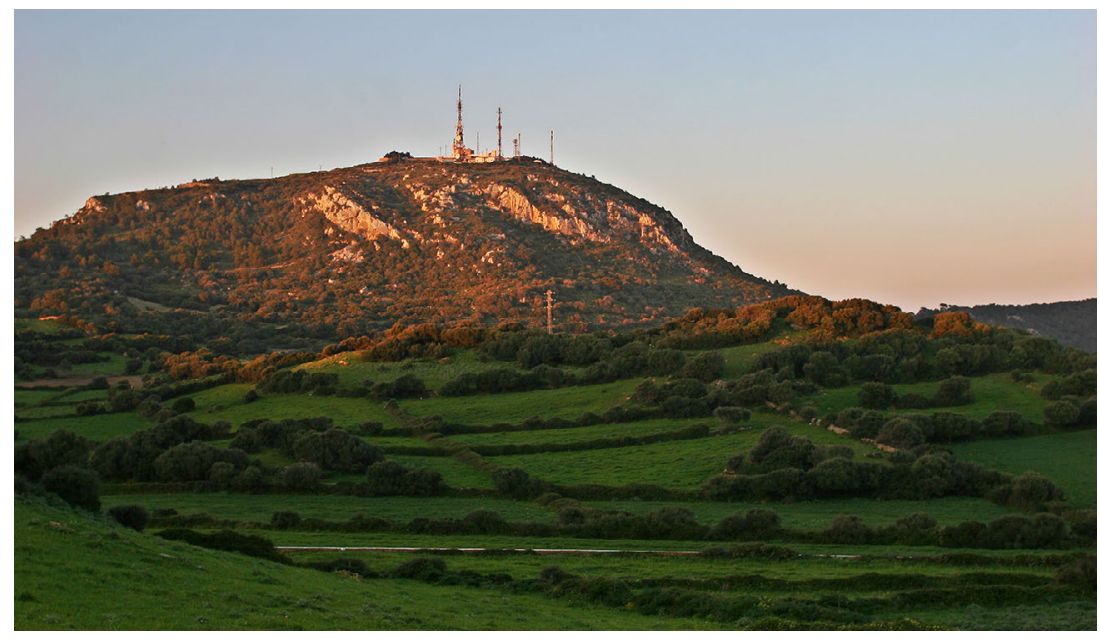

Los nombres geográficos que designan terrenos llanos (pla, plana...) y que destacan la horizontalidad de ciertos fragmentos del territorio menorquín apenas llegan al 3\% de su grupo y aún así su presencia es superior que en la isla de Ibiza. Por su parte, los topónimos que indican la inclinación del terreno, casi exclusivamente mediante los genéricos costa y coster, y sobre todo la fuerte presencia de éste último ya detectada en otros trabajos sobre la terminología geográfica de Menorca (Ordinas, 1992), representan el 3,5\%, lo que la convierte en la isla donde se obtiene el mayor porcentaje de orónimos que aluden a la pendiente del terreno.

El 3,7\% de la toponimia orográfica hace referencia a cavidades naturales: simas (avenc), cuevas (cova), grutas (balma), abrigos (abric), agujeros (forat), etc. La escasa representación de la mayoría de estas microformas debe ser atribuida a la deficiencia de la recolección toponímica que, por sus características, no prioriza este tipo de microtopónimos, no tan esenciales en la cartografía a la vez que sus reducidas dimensiones facilitan a que pasen más desapercibidos.

Figura 9. Toponimia relativa a la orografía terrestre y marítima.

\section{Medio físico: orografía terrestre y marítima}
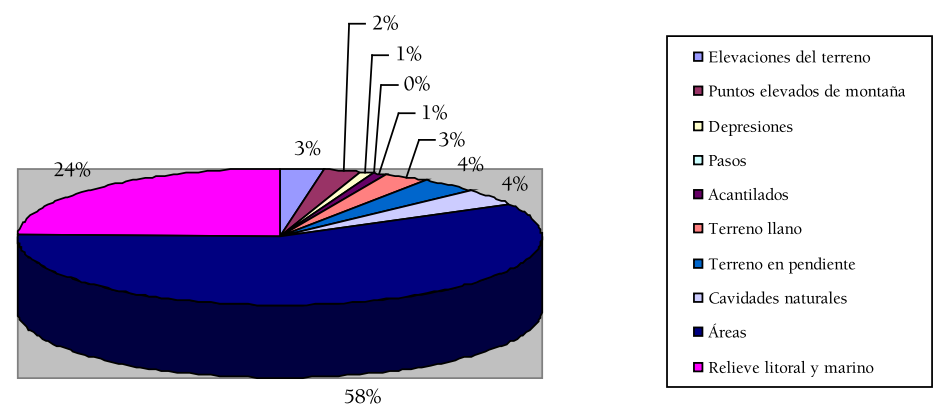

En el extremo opuesto en cuanto a representación, con un 58,7\%, destaca el grupo que identifica a una diversidad de áreas, de connotaciones un tanto imprecisas y con algunos genéricos que no pertenecen propiamente al ámbito de la geografía física. En este caso, el criterio de homogeneidad en la rotulación cartográfica, origen de la clasificación, no se adecua al geográfico como prueba la agrupación de conceptos tan diversos como partida, peça, sort, camp, tros, bosc, obac, obaga, solà, solana, tanca, pleta, devesa, era, hort, horta, paratge y mirador. La gran abundancia de los terrenos cercados o vallados, denominados tanca (plural, tanques) en Menorca, es en gran medida culpable de lo elevado del porcentaje. 
Por último, bajo la denominación de relieve y litoral marino se agrupan pequeños archipiélagos, islas e islotes, cabos, puntas, istmos, arrecifes, farallones, playas, arenales, dunas, calas, puertos naturales y cualquier otro accidente costero o litoral que, en conjunto, suman el 24,3\% de los topónimos orográficos. A pesar de ello, gran parte de la toponimia corresponde a la denominación, indefinida e imprecisa, de costa litoral. El hecho de la insularidad así como sus $285,7 \mathrm{~km}$ de costa articulada pueden explicar la importancia porcentual de este grupo toponímico.

\subsubsection{Hidrografía}

La toponimia relativa a la hidrografía supone el 13,5\% del total de los topónimos del medio físico. Se ha dividido en cinco grupos: masas naturales de agua, masas artificiales de agua, cursos naturales de agua, cursos artificiales de agua y obras hidráulicas. Los nombres relativos a las masas de agua suman más de la mitad de los hidrónimos, destacando los correspondientes a las de origen natural (con un 43,5\%, porcentaje que casi dobla el homónimo para el conjunto del archipiélago, que es de un 23\%) que designan albuferas, humedales, marismas, bahías, calas, lagunas, estanques, estrechos y mares. Con sólo un 9,9\% se sitúan las masas artificiales de agua formadas por balsas, cisternas, pozos y depósitos. Su porcentaje es algo inferior al del conjunto de las islas, con un $11,9 \%$.

Figura 10. Cala Galdana, una de las más representativas del litoral meridional, en la desembocadura del barranc d'Algendar.

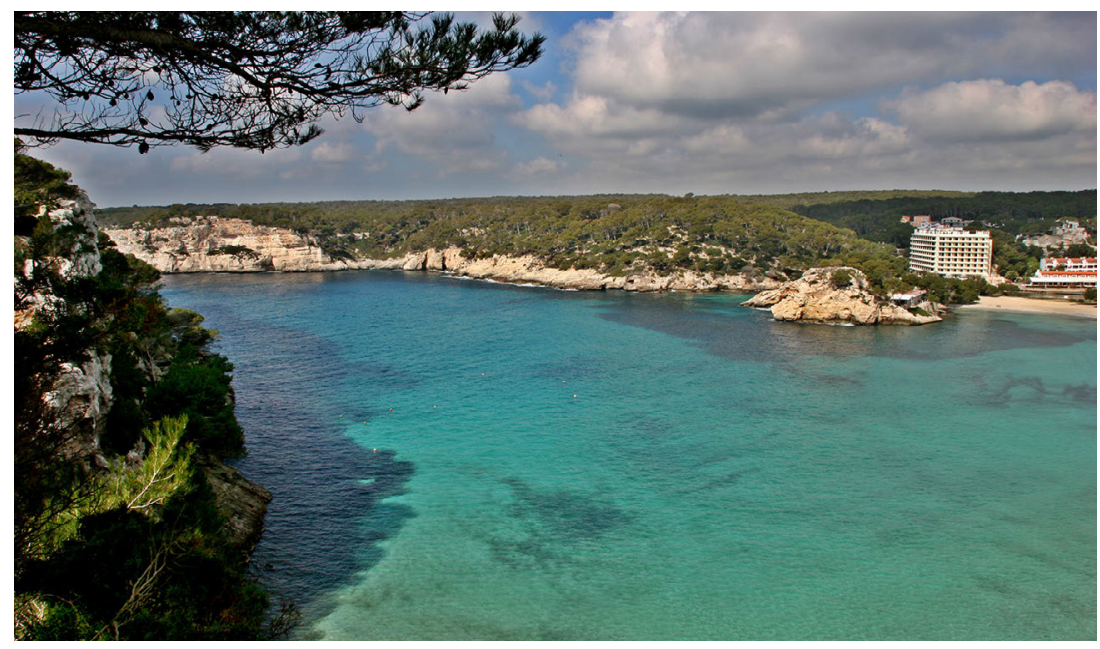

Los topónimos que identifican los cursos de agua naturales conforman el segundo grupo en tamaño (35,5\%), aunque alejado de la media de la islas que llega al 57,8\%, e incluyen las denominaciones de torrentes, barrancos, rieras, ramblas, saltos y fuentes. Los cursos artificiales están representados por canales y acequias, con un $9 \%$ de representación, algo superior a la media insular del 5,8\%. Finalmente, la toponimia relativa a obras hidráulicas que en el caso de Menorca se reduce casi íntegramente a norias, supone un 1,9\%.

Figura 11. Toponimia relativa a la hidrografía.

\section{Medio físico: hidrografía}

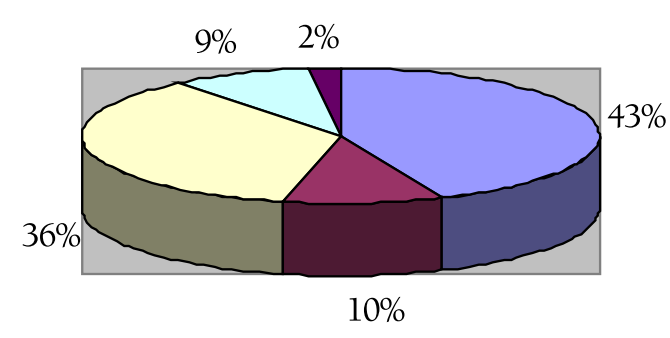

$\square$ Masas naturales de
agua
$\square$ Masas artificiales de
agua
$\square$ Cursos naturales
$\square$ Cursos artificiales
$\square$ Obras hidráulicas




\section{JERARQUIZACIÓN TOPONÍMICA Y DESCRIPCIÓN DEL PAISAJE MENORQUÍN}

La jerarquización toponímica mediante el número de frecuencias y su porcentaje correspondiente, permite alcanzar un nivel de análisis más detallado. Para ello, hemos seleccionado las categorías toponímicas que presentaban las frecuencias más elevadas de las entradas de la codificación del ICC. En la tabla siguiente quedan reflejadas, ordenadas de mayor a menor, junto con el porcentaje que suponen sobre el conjunto de la toponimia isleña.

Tabla 2. Menorca. Topónimos con mayor número de frecuencias.

\begin{tabular}{|c|c|c|c|}
\hline Topónimos & $\begin{array}{l}\text { Número de } \\
\text { frecuencias }\end{array}$ & $\begin{array}{c}\% \text { sobre el } \\
\text { total }\end{array}$ & Adscripción temática \\
\hline Tanca, pleta & 1.647 & 24,5 & Agricultura/Ganadería \\
\hline Casa (aislada) & 1.156 & 17,2 & Poblamiento \\
\hline Punta, costa & 755 & 11,2 & Orografía litoral \\
\hline Bosc, marina, garriga & 309 & 4,6 & Vegetación \\
\hline Camí & 255 & 3,8 & Poblamiento \\
\hline Cala & 209 & 3,1 & Orografía (litoral) \\
\hline Camp, sort & 169 & 2,5 & Agricultura/Ganadería \\
\hline Cova, forat & 145 & 2,1 & Orografía \\
\hline Torrent, barranc & 139 & 2,0 & Hidrografía natural \\
\hline Costa, coster (falda) & 137 & 2,0 & Orografía (interior) \\
\hline Barraca, cabana & 137 & 2,0 & Poblamiento \\
\hline Pla, plana & 115 & 1,7 & Orografía (interior) \\
\hline Puig, penya, roca, bony & 88 & 1,3 & Orografía (interior) \\
\hline Mola, pujol, turó & 82 & 1,2 & Orografía (interior) \\
\hline Hort, horta & 75 & 1,1 & Agricultura/Ganadería \\
\hline Talaiot & 63 & 0,9 & Poblamiento (prehistoria) \\
\hline Urbanització & 55 & 0,8 & Poblamiento \\
\hline Platja & 50 & 0,7 & Orografía (litoral) \\
\hline Illa, illot & 47 & 0,7 & Orografía (litoral) \\
\hline Font & 46 & 0,7 & Hidrografía (natural) \\
\hline Paratge & 43 & 0,6 & Vegetación \\
\hline Escull, faralló & 43 & 0,6 & Orografía (litoral) \\
\hline Canal (comellar) & 40 & 0,6 & Orografía (interior) \\
\hline Pou & 35 & 0,5 & Hidrografía (humana) \\
\hline Poblat, necròpolis & 31 & 0,5 & Poblamiento (prehistoria) \\
\hline Cap & 31 & 0,5 & Orografía (litoral) \\
\hline Era & 23 & 0,3 & Agricultura/Ganadería \\
\hline Talaia, torre de defensa & 20 & 0,3 & Poblamiento \\
\hline
\end{tabular}

Asimismo hemos adscrito cada una de las entradas toponímicas de mayor frecuencia a una temática definidora de su realidad geográfica, permitiendo distinguir entre topónimos relacionados con la orografía (precisando incluso si es interior o litoral), la hidrografía (natural o humana), la vegetación, el poblamiento (precisando si es prehistórico) y las actividades agrícolas y/o ganaderas. A partir de una dicotomía básica, se observa cómo las tipologías correspondientes a la toponimia humanizada acumulan un total del $54,4 \%$, frente a las que corresponden a toponimia relativa al medio natural, cuyo porcentaje global es del 33,6\%. No obstante, el siguiente gráfico permite jerarquizar cada una de las temáticas antes descritas y que de alguna manera caracterizan el paisaje menorquín. La encabezan los topónimos relacionados con la práctica de la agricultura y/o ganadería que suponen el 32\% del conjunto de esta especie de top ten -en realidad top 28-, de los topónimos con mayores frecuencias; seguidos de cerca por los grupos correspondientes a la orografía y el poblamiento, ambos con un 29\%. Algo más lejos quedan los grupos toponímicos relativos a la vegetación (6\%) y la hidrografía (4\%). 
Figura 12. Adscripción temática de la toponimia.

\section{MENORCA \\ Adscripción temática de la toponimia}

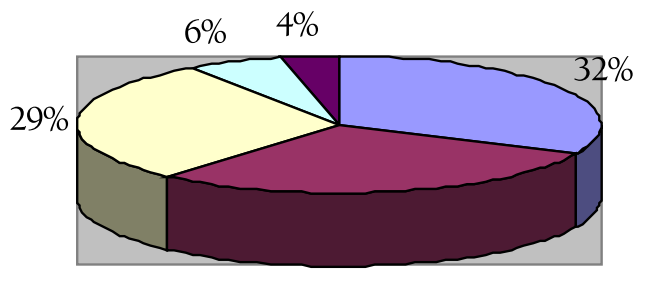

$\square$ Agricultura/Ganadería
$\square$ Orografía
$\square$ Poblamiento
$\square$ Vegetación
$\square$ Hidrografía

$29 \%$

Si pormenorizamos en el detalle del análisis, en el conjunto de topónimos agrarios, la presencia de eras, en correspondencia casi unívoca a la de los llocs, nos recuerda la Menorca tradicional y agraria, donde la era constituía una parte fundamental de la infraestructura de las explotaciones.

Respecto a la orografía, se constata un mayor peso de los orónimos litorales $(16,8 \%)$ frente a los correspondientes al interior insular $(6,8 \%)$, aunque un $2,1 \%$ (cova, forat) podrían adjudicarse a cualquiera de los anteriores. La importante extensión y articulación del litoral menorquín explican por sí mismas esta distribución, aunque también resulta representativa de la orografía menorquina, la numerosa presencia de laderas y faldas (costa y coster), que conforman un paisaje en el que predominan los cerros y donde la fuerte presencia de tales términos ya fue señalada en un estudio monográfico sobre la terminología geográfica del paisaje natural menorquín (Ordinas, 1992). Tampoco puede negarse la significatividad territorial que en Menorca tienen los barrancos que surcan la comarca del Migjorn a pesar de su relativo escaso número. En este caso, quizá debería explicarse, no por el principio de la transparencia sino, tal vez, por el de la excepcionalidad, un tipo particular de comportamiento toponímico en el que los nombres de lugar, en contextos determinados, tienden a reflejar primero las características excepcionales del entorno donde se insertan antes que las "típicas" (Tort, 2003).

En el campo del poblamiento destaca la importante presencia de topónimos relativos a talayots, poblados y necrópolis como reflejo del abundante patrimonio arqueológico de la isla. Talaiot, naveta y taula son algunos de los principales genéricos arqueotoponímicos que se detectan en la isla. Entre los fitotopónimos, los casos de bosc, garriga, pero sobre todo marina, tampoco resultan extraños dentro del contexto paisajístico menorquín en cuanto a la vegetación natural. Asimismo, los hidrónimos naturales $(2,7 \%)$ se imponen claramente sobre los artificiales o humanizados $(0,5 \%)$.

Figura 13. La Naveta des Tudons, uno de los más emblemáticos monumentos arqueológicos que tanto abundan y caracterizan el paisaje menorquín.

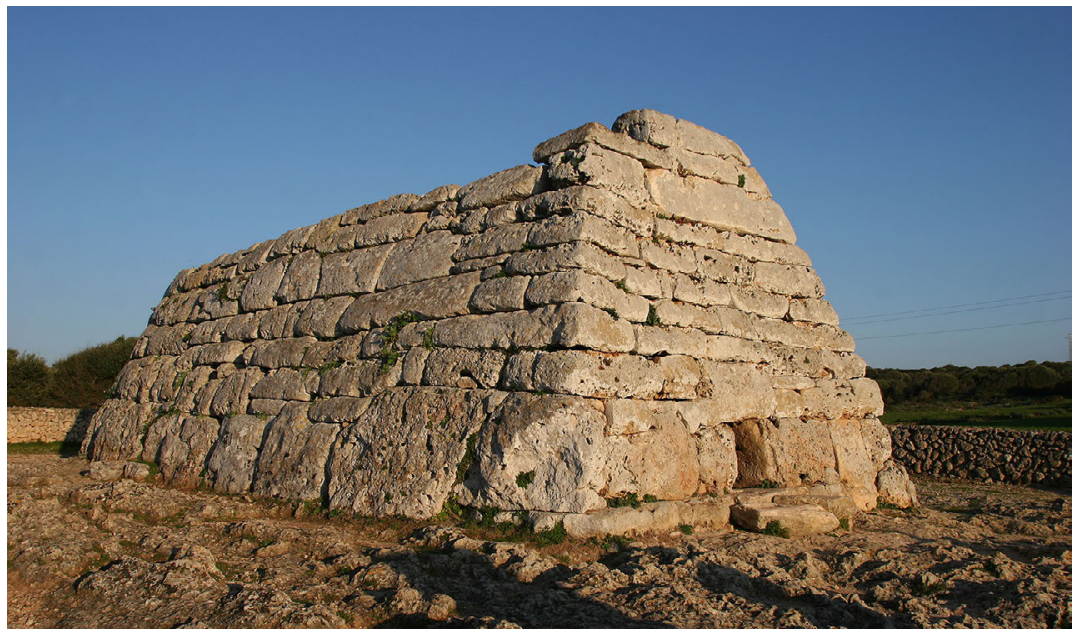




\section{LA PERCEPCIÓN DEL PAISAJE A TRAVÉS DE LA TOPONIMIA Y LOS PRINCIPIOS DE TRANSPARENCIA Y SIGNIFICATIVIDAD TERRITORIAL}

A través de la toponimia podemos percibir el paisaje al quedar descritos y definidos en ella sus elementos más característicos, tanto pretéritos como actuales, de manera que en el conjunto de los topónimos queda sintetizado el paisaje, actual e histórico. Si, parafraseando a Darby (1957), "el conocimiento del territorio nos da las claves del significado de los nombres", podemos inferir que, al revés, también a través de los nombres obtendremos el conocimiento del territorio. La abundante información que proporcionan los nombres geográficos, a veces oculta por el paso del tiempo y las transformaciones y deformaciones que acarrea, puede ser analizada y resulta de gran utilidad para la aprehensión del territorio. La toponimia, además, no se limita a reflejar solamente lo habitual, por abundante y repetitivo, característica que refleja el llamado principio de transparencia, sino también lo excepcional, por su rareza y el valor intrínseco que siempre conlleva y que constituye el principio de excepcionalidad.

Así pues, el análisis geográfico del corpus toponímico de Menorca y de los resultados obtenidos a partir de su clasificación y contabilización, evidencian el cumplimiento del principio de transparencia, por el que sus principales y más característicos rasgos del paisaje y del territorio quedan reflejados en la toponimia de forma sistemática, de modo que hay una clara sintonía y correspondencia entre ambos. Por otro lado, también se detectan casos que se acercan a una mayor singularidad, pero que no pierden la significatividad territorial, constituyendo el llamado principio de significatividad territorial, de forma que incluyen aspectos de la geografía de una determinada región que se muestran de alguna manera destacados o relevantes con respecto al resto de aspectos de esta región, aunque, a menudo, esta relevancia no es explícita o tan explícita, ya que no cuenta con un importante apoyo numérico de topónimos, sino que exige un conocimiento y una interpretación por parte del observador del medio geográfico al que se hace referencia (Tort, 2003). El análisis de la toponimia menorquina permite constatar el cumplimiento de los principios de transparencia y de significatividad territorial que los geógrafos que trabajan e investigan la toponimia, ya desde la escuela de Quebec, han formulado y aplicado a diversos territorios del planeta.

Del análisis de los genéricos presentes en los topónimos menorquines y de la su intensidad o frecuencia, podemos descubrir asimismo una clara correspondencia entre ellos y los rasgos fundamentales del espacio en que se sitúan además de la terminología geográfica propia de cada territorio en cuestión (Ordinas, 2001). El bajo nivel de urbanización y rururbanización, - al menos en comparación con el resto de las Baleares -, que presenta el paisaje menorquín queda también patente en la toponimia, donde buena parte de los genéricos más frecuentes corresponden semánticamente a los aspectos físicos del paisaje.

Figura 14. El Barranc d'Algendar es uno de los barrancos que configuran el paisaje del Migjorn de Menorca, marcando la divisoria entre los municipios de Ciutadella y Ferreries.

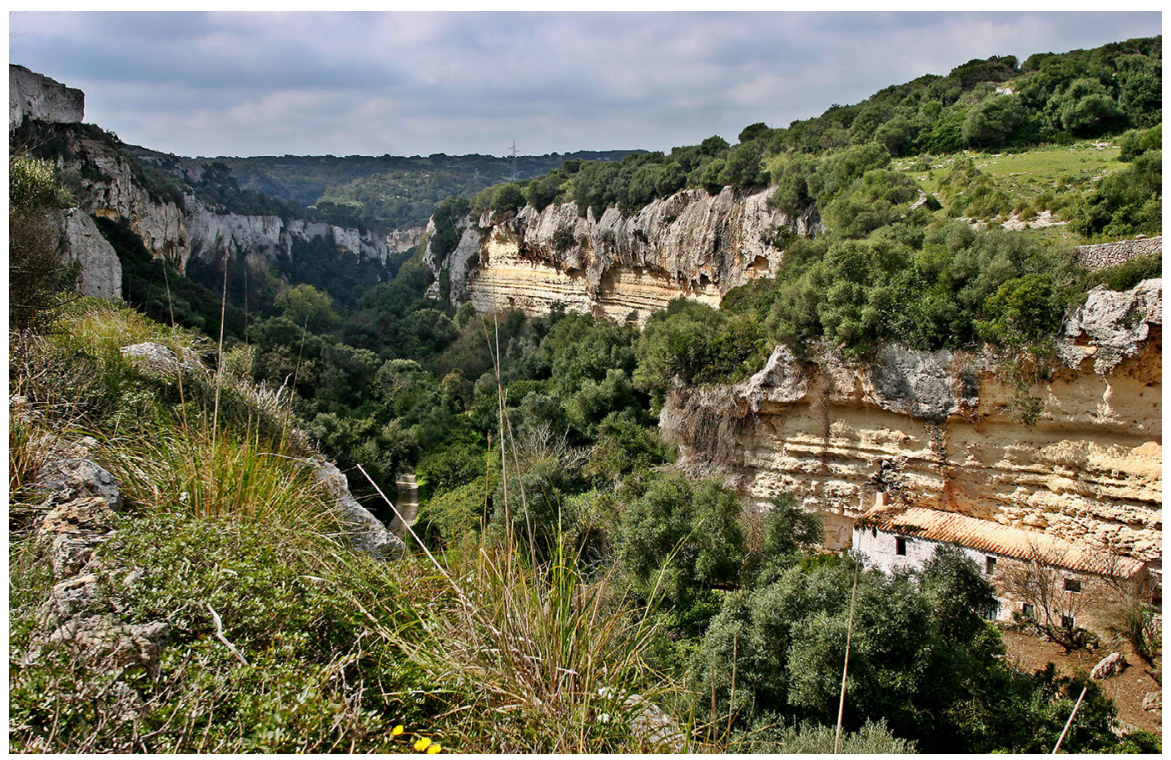


La presencia dominante de genéricos toponímicos referidos al campo de la geomorfología ya deja entrever el mayor impacto del relieve y de sus accidentes dentro de este contexto insular. Dos factores son los de mayor peso a la hora de explicar esta abrumadora mayoría de los orónimos: la insularidad, origen de un importante número de topónimos, articuladores de los 285,7 kilómetros del litoral, y la intensa accidentalidad del territorio, consecuencia de la acción erosiva sobre dos sistemas bastante diferenciados: la fuerte y alterna presencia de plans y costers en la mitad norte de la isla coincidiendo con la zona de afloramiento del Devónico, de manera que sólo estos dos genéricos conjuntamente suponen el 84\% de los topónimos incluidos en el apartado que excluye las formas positivas y negativas. Y, por otra parte, la significativa presencia de los grandes barrancos que surcan la mitad sur formada por mioceno. Es destacable junto con barranc, el apelativo canal que aparece fuertemente extendido por toda la isla constituyéndose en el máximo representante de las depresiones alargadas cuando no llegan a la magnitud del barranco.

Otro rasgo diferenciador del paisaje físico que queda igualmente reflejado en la toponimia es la escasa presencia del relieve positivo interior, especialmente a nivel de mesotoponimia, sin genéricos destacados y con sólo una muy discreta representación de puig, pujol y serra. Tal penuria contrasta con la diversidad de las formas litorales. Bastaría con enumerar las condiciones climáticas, la escasez de agua y la presión humana del territorio menorquín para esbozar las razones de la débil representación obtenida por los hidrónimos y fitotopónimos. Al respecto de éstos últimos, una de las peculiaridades de la designación en Menorca de las masas vegetales es la práctica ausencia del genérico bosc, que contrasta con la masiva presencia del término marina y su forma diminutiva marineta, más acorde con los factores edafoclimáticos de la isla y de la siempre cercana influencia marina.

En definitiva, resulta evidente que en la toponimia de Menorca se encuentra una terminología geográfica con suficiente personalidad que si bien presenta, evidentemente, afinidades con las del resto de las islas, no deja por ello de conjugar y de aportar componentes definidores y suficientemente diferenciados del resto del archipiélago. A ello se añade la innegable significatividad territorial del conjunto de su toponimia que al identificar y resaltar exhaustivamente los elementos del territorio, permite asimismo describir su particular paisaje a través de todos y cada uno de los principales rasgos que lo constituyen.

\section{BIBLIOGRAFÍA}

\section{CALDENTEY, J. et al.:}

- (2006a):"El paisatge vitícola actual i històric de Mallorca a través de la toponímia", en XVIII Jornada d'Antroponimia i Toponimia (2005); pp. 63-70. Universitat de les Illes Balears, Palma.

- (2006b): "La fitotoponímia com a element definidor del paisatge. El cas de Selva", en XVIII Jornada d'Antroponímia i Toponímia (2005), pp. 109-121. Universitat de les Illes Balears, Palma.

\section{CASASNOVAS MARQUES, L.:}

- (1951): "Alrededor de nuestra toponimia", en El Iris. Menorca.

- (1955): "Nomenclatura agrícola en la toponimia menorquina", en Miscel-lània Filològica dedicada a Mn. Griera, no I, pp. 159-174.

DARBY, H.C. (1957): "Place names and geography", en The Geographical Journal, nº 123, pp. 387-392.

GRIMALT, M. et al.:

- (2006) "El paisatge vegetal de Santa Maria del Camí a través de la fitotoponímia", en V Jornades d'estudis locals (2006), pp. 319-327. Ajuntament de Santa Maria del Camí, Santa Maria del Camí.

- (2009): "El paisatge vegetal de Menorca a través de la fitotoponímia", en Documents d'Anàlisi Geogràfica, n 55, pp. 93-115.

MASCARÓ PASARIUS, J.:

- (1946-51): Mapa General de Menorca. Imp. M. Sintes Rotger. Maó.

- (1953): Nomenclátor de Menorca. Catálogo de accidentes de la costa. Catálogo de fincas rústicas y breves notas arqueológicas. Impr. Gabriel Camps. Ciutadella. 
- (1973): Nomenclátor de Menorca II. Catálogo de fincas rústicas. Imp. Allés. Ciutadella.

- (1976): Mapa de Menorca. Gràfiques Miramar. Palma de Mallorca.

- (2005): Corpus de toponímia de Menorca. Ed. Hora Nova. Palma.

ORDINAS GARAU, A.:

- (1991): "Menorca a través de la seva toponímia", en El Mirall, no 47, pp. 19-21.

- (1992): "Oronímia, hidronímia i fitonímia. Una aproximació a la terminologia geogràfica del paisatge natural menorquí", en Treballs de Geografia, no 44, pp. 145-152.

- (1994): Actualització del recull bibliogràfic de toponímia i antroponímia de les Illes Balears. Quaderns de toponímia, onomástica i cultura popular, $\mathrm{n}^{\circ}$ 2. Ed. Universitat de les Illes Balears. Palma, $119 \mathrm{p}$.

- (2001): Geografia i Toponímia a les Illes Balears. La terminología geogràfica en els noms de lloc. Ed. Moll. Mallorca.

- (2004): "Els ensenyaments fisiogràfics de la toponímia. Genèrics orogràfics del Migjorn". En Joan J. Fornós, Antoni Obrador, Vicenç M. Rosselló (eds.) Història natural del Migjorn de Menorca: el medi físic i l'influx humà, Monografies de la Societat d'Història Natural de les Balears, nº 11, pp. 315-326.

ORDINAS GARAU, A. et al.:

- (2012): "La toponímia del Mapa topogràfic de Menorca a escala 1:5.000. Una anàlisi geográfica", en Territoris, $\mathrm{n}^{\circ}$ 8, pp.177-192.

- (2007): "Marines i garrigues a Mallorca, geografia de dos genèrics toponímics", en XIX Jornada d'Antroponímia i Toponímia (2006), pp. 223-229. Universitat de les Illes Balears, Palma.

ORDINAS, A. y BINIMELIS, J. (2002): "Vindicación de la toponimia como instrumento para el estudio del cambio rural. Rururbanización y neotoponimia en los municipios de Selva e Inca (Mallorca)", en Los espacios rurales entre el hoy y el mañana, pp. 285-293. Universidad de Cantabria, Santander.

PICORNELL, C. (1982): "La nova toponímia de les Illes Balears. Una aportació als topònims sorgits arrel del turisme", en Societat d'Onomàstica. Butlletí Interior, nº X, pp. 86-100.

POIRIER, J. (1965): “Toponymie. Méthode d'enquête”, en Les Presses de l'Université Labal. Quebec.

ROSSELLÓ VERGER, V. M.:

- (2001): "Fitotopònims de Menorca", en Cuadernos de Geografía, nº 69-70, pp. 187-194.

- (2004): Toponímia, geografia i cartografia. Ed. Universitat de València. València.

SAUER, C.O. (1956): "The Education of a Geographer", en Annals of the Association of American Geographers, nº46, pp. 287-299.

TORT, J.:

- (2000): "La geografia, els noms de lloc i la descripció del territori"; En Mateu, J.F; Casanova, E. (eds.) Estudis de Toponímia Valenciana. Ed. Denes. València, pp. 491-497.

- (2000): "Els noms de lloc i la geografia. La toponímia com a eina per a la conceptualització de l'espai", en Societat d'Onomàstica. Butlletí Interior, nº. 83, pp. 86-98.

- (2001): "La toponímia com a camp de coneixement interdisciplinari. Algunes bases teòriques i epistemològiques per a l'estudi dels noms de lloc", en Scripta Nova, no 86.

- (2002): La toponimia del Baix Camp. Una interpretació geogràfica. Ed. Associació d'Estudis Reusencs. Reus.

- (2003): "A propòsit de la relació entre toponímia i geografia: el principi de 'significativitat territorial”" En Casanova, E.; Valero, L. R. (eds.) XXIX Col-loqui de la Societat d'Onomàstica; Ed. Denes. Teulada, pp. $675-688$.

- (2012): "Toponímia, paisatge i diferenciació del territori'”. En Tort,J. (ed.) Denoms i de llocs. Miscel-lània d'homenatge a Albert Manent i Segimon; Ed. Societat d'Onomàstica. Sant Adrià de Besòs, pp. 463 - 472.

VIDAL DE LA BLACHE, P. (1888-1889): "Des divisions fondamentales du sol français", en Butlletin Littéraire, II, pp. 1-7/49-57. 